\title{
Device closure of ventricular septal defect: Initial experience in Nepal
}

\author{
Chandra Mani Adhikari', Manish Shrestha ${ }^{2}$, Subash Chandra Shah ${ }^{3}$, Amrit Bogati $^{4}$, \\ Sachin Dhungel ${ }^{5}$, Kiran Prasad Acharya ${ }^{6}$, Poonam Sharma ${ }^{7}$, Shilpa Aryal ${ }^{8}$, \\ Urmila Shakya ${ }^{9}$
}

\begin{abstract}
${ }^{1}$ Cardiologist, Department of Cardiology, Shahid Gangalal National Heart Centre, Nepal, ${ }^{2}$ Pediatric Cardiologist, Department of Pediatric Cardiology, Shahid Gangalal National Heart Centre, Nepal, ${ }^{3,7,8}$ Registrar, Department of Pediatric Cardiology, Shahid Gangalal National Heart Centre, Nepal, ${ }^{4,5}$ Registrar, Department of Cardiology, Shahid Gangalal National Heart Centre, Nepal, ${ }^{6}$ Resident, Department of Cardiology, Shahid Gangalal National Heart Centre, Nepal, ${ }^{9}$ Consultant Pediatric Cardiologist, Department of Pediatric Cardiology, Shahid Gangalal National Heart Centre, Nepal
\end{abstract}

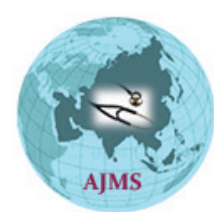

\section{A B S T R A C T}

Background: Device closure is an attractive alternative in the management of Ventricular Septal defect (VSD). Aims and Objectives: The aim of the study was to access the safety and early outcome of VSD device closure at Shahid Gangalal National Heart Centre, Nepal. Materials and Methods: The study was single center, retrospective study. All the VSD cases that were attempted for VSD device closure during December 2016 to February 2019 were included. Catheterization laboratory records for VSD type and size, Device type and size were retrospectively reviewed. Hospital records were reviewed for in-hospital complications. Results: Sixty-one VSD cases were attempted for device closure. VSD was successfully closed in 55 (90.1\%) patients. The mean age of the patient was 11.1 years. Twenty-nine (52.7\%) were female and $26(47.3 \%)$ were male. Perimembranous VSD was present in $49(89 \%)$ and muscular VSD in $6(11 \%)$ patients. The size of VSD ranged between 2 and $12 \mathrm{~mm}$ (Mean $5.4 \mathrm{~mm}$ ). The VSD was closed with Amplatzer duct occluder I, Amplatzer duct occluder II, Amplatzer muscular VSD occluder and Memopart PDA device in 24 (43.7\%), 26 (47.3\%), 4 (7.2\%) and one patient $(1.8 \%)$ patients respectively. The postoperative complications were insignificant residual leak across device in $2(3.6 \%)$ patients, mild pericardial effusion in one $(1.8 \%)$ patient. None of the patient had new onset tricuspid regurgitation, aortic regurgitation and complete heart block. One patient developed Right bundle branch block, one developed Left bundle branch block, and one developed junctional rhythm. There was no mortality. Conclusion: VSD device closure can be safe and effective if patients are selected properly.

Key words: Amplatzer duct occluder I; Amplatzer duct occluder II; Amplatzer muscular VSD occluder; Ventricular Septal defect

\section{INTRODUCTION}

Ventricular septal defect (VSD) is a common congenital heart defect in both children and adults. ${ }^{1}$ Itoccurs in $50 \%$ of all children with congenital heart disease ${ }^{2}$ and in $20 \%$ as an isolated lesion. ${ }^{3}$ In addition to congenital VSDs, VSDs can be acquired and result from trauma or following a myocardial infarction.
http://nepjol.info/index.php/AJMS DOI: 10.3126/ajms.v10i4.24176 E-ISSN: 2091-0576 P-ISSN: 2467-9100
VSDs are openings in the ventricular septum and may occur anywhere in the septum. They are classified according to their location. ${ }^{1,4}$ Approximately $70-80 \%$ of defects are perimembranous in location. Another 5-20\% are muscular innature. ${ }^{5,6}$ Outlet VSDs account for 5-7\% of all VSDs. Inlet VSDs constitute another $5-8 \%$ of VSDs. ${ }^{4}$ Surgical closure of muscular and perimembranous VSD has a low mortality and morbidity and has been 
the standard treatment for patients with pulmonary flow overload and heart failure. ${ }^{7}$ VSD device closure has been shown to be a viable alternative whenever possible. ${ }^{8}$ There are very report of VSD device closure of outlet VSD. Whereas inlet VSDs are not amenable to device closure since there is no supporting tissue between the margins of the defect and the atrioventricular valve tissue. ${ }^{4}$ Acquired VSDs complicated by myocardial infarction occur in $0.2 \%$ of patients in the thrombolytic era and are associated with a very high mortality rate. ${ }^{9}$ VSD post MI can be managed with device closure. Traumatic VSDs have only rarely been reported and reports of percutaneous closure are scarce..$^{10,11}$

There are multiple studies around the world about the safety and efficacy of VSD device closure. Till date there is no study from Nepal about the safety and efficacy of VSD device closure. This study aims to study the safety and efficacy of VSD device closure in Nepal.

\section{MATERIALS AND METHODS}

This study was a single center, retrospective cross sectional study conducted at Shahid Gangalal National Heart Centre, Kathmandu, Nepal. All the VSD cases with who were attempted for VSD device closure during December 2016 to February 2019 were retrospectively reviewed. Catheterization laboratory records for age, gender, VSD type, VSD size, Device type, device size, procedural approach were retrospectively reviewed. Hospital records were reviewed for in-hospital complications. This study was approved from Institutional review committee of National Heart Centre, Kathmandu, Nepal. All the variables were entered into the Statistical Package for Social Sciences software, version 14 (SPSS Inc) for data analysis. Descriptive statistics were computed and presented as means for continuous variables categorical variables were reported in percentages.

\section{Procedure}

Device closure of perimembranous VSD was performed under conscious sedation and under local anesthesia. Access was through the femoral vein and artery. Heparin $(100 \mathrm{IU} / \mathrm{kg})$ and intravenous antibiotic were administrated. The procedure was performed under fluoroscopic control. Left ventricular angiography was performed at $60^{\circ}$ to $20^{\circ}$ left anterior oblique projection/cranial to profile the perimembranous and angiography of ascending aorta to profile the aortic valves. Left ventriculography combine with intraprocedural transthoracic echocardiogram (TTE) were used to obtain the location, size of VSD, and its relationship with adjacent aortic valves. The diameter of VSD was measured at largest diastolic phase on the left ventricular side and was calculated by integrating data from the TTE and angiography measurement. The device was selected 1 to $2 \mathrm{~mm}$ larger than the measured VSD diameter.

The defect was crossed in a retrograde fashion from the left ventricle using Judkins right catheter and an exchange floppy guide wire was advanced into the pulmonary artery or the superior or inferior vena cava. The wire was then snared to establish an arteriovenous circuit through femoral vein approach on the same side. An appropriate size of dilator and long sheath was advanced to the left ventricle through the arteriovenous circuit and positioned beneath the aortic valve. The device screwed on the delivery cable was passed through the delivery sheath. The distal disc was opened in the aorta or left ventricle, and the whole system was withdrawn. The right ventricular disc was opened in the right ventricle after confirming that the left ventricular disc was in the correct position.

In case where ADO II was used the VSD was crossed in a retrograde fashion from the aorta using a Terumo ${ }^{\circledR}$ guide wire. A Judkins right catheter was crossed across the VSD. ADO II device was loaded in the loader. The distal disc RV disc was opened in right ventricle, and the whole system was withdrawn. The proximal (LV ventricular) disc was opened in the left ventricle.

The VSD can also be crossed in anante grade fashion from the RV using a Judkins right catheter with Terumo ${ }^{\circledR}$ guide wire which were advanced through the defect and into the ascending aorta or LV apex. The Terumo wire was then replaced with a super stiff guidewire. An appropriate size delivery system was advanced through the VSD from the femoral vein and into the ascending aorta or LV apex. The dilator and guide wire were removed, and the chosen ADO I or similar device was loaded and advanced to the appropriate position. Under echocardiographic guidance, the device was partially opened in the ascending aorta, and then gently pulled back through the valve into the left ventricle. The retention skirt was pulled into the defect, and the rest of the device deployed by pulling back the delivery sheath.

After verification of device position, the aortic and tricuspid valves by TTE and angiography, the device was released. Patients were transferred to general wards; continuous ECG monitoring was used for $24 \mathrm{~h}$ after the procedure. Clinical examination, chest X-ray, TTE, and ECG were done before the hospital discharge. In-hospital complication was recorded. 


\section{RESULTS}

During the study period sixty-one cases were attempted for device closure. VSD was successfully closed in 55 (90.1\%) patients. Among the six attempted case one was post myocardial infarction case. The procedure was abandoned as its anatomy was not suitable for device closure. In the remaining five cases which were all perimembranous VSD, procedure was abandoned due to development of AR in four case and unstable device in one case. The mean age of the patient was 11.1 years. Twenty-nine 29 (52.7\%) were female and $26(47.3 \%)$ were male as shown in Table 1. Perimembranous VSD in 49 (89\%) and muscular VSD in $6(11 \%)$ patients as shown in Table 1 . The size of VSD ranged between 2 to $12 \mathrm{~mm}$ with the mean $5.4 \mathrm{~mm}$. The VSD was closed with Amplatzer duct occluder I, Amplatzer duct occluder II, Amplatzer muscular VSD occluder and Memopart PDA device in 24 (43.7\%), $26(47.3 \%), 4(7.2 \%)$ and one patient $(1.8 \%)$ patients respectively as shown in Table 2 . Ante grade technique was used in 5 cases. In all other cases retrograde technique was used to cross the VSD.

The postoperative complications were insignificant residual leak across device in $2(3.6 \%)$ patients, mild pericardial effusion in one $(1.8 \%)$ patient. None of the patient had new onset tricuspid regurgitation, aortic regurgitation and complete heart block. One patient developed Right bundle branch block, one developed Left bundle branch block, and one developed junctional rhythm. Patient recovered with steroid therapy. All these bundle branch block and

Table 1: Demographics (successful cases) N=55

\begin{tabular}{lc}
\hline Clinical characteristics & $\mathbf{N}(\%)$ \\
\hline Male & $26(47.3)$ \\
Female & $29(52.7)$ \\
Perimembranous VSD & $49(89)$ \\
Muscular VSD & $6(11)$ \\
\hline
\end{tabular}

\begin{tabular}{lc} 
Table 2: Device types and size $\mathbf{n = 5 5}$ \\
\hline Device type and size & $\mathbf{N}$ (\%) \\
\hline ADO I & \\
$6 \times 8$ & 3 \\
$8 \times 10$ & 8 \\
$10 \times 12$ & 13 \\
ADO II & \\
$4 \times 6$ & 6 \\
$5 \times 4$ & 8 \\
$6 \times 4$ & 8 \\
$6 \times 6$ & 4 \\
Muscular VSD device & \\
6 & 1 \\
12 & 1 \\
14 & 2 \\
Memopart & \\
$10 \times 12$ & 1 \\
\hline
\end{tabular}

Asian Journal of Medical Sciences | Jul-Aug 2019 | Vol 10 | Issue 4 junctional rhythm occurred in perimembranous VSD cases. There was no mortality.

\section{DISCUSSION}

This study highlights the initial experience on VSD device closure in the country. Our success rate of $90 \%$ with low complication rates is encouraging though VSD device closure is much more complicated procedure than device closure of atrial septal defects and patent ductus arteriosus. Advancements in catheter techniques and devices are leading into the era of device closure of VSDs. The benefits of avoiding bypass are intuitive, and the relative ease of placement makes this procedure ultimately attractive. ${ }^{12}$

Our success rate of $90 \%$ and few complications is comparable to international studies. Carminati et $\mathrm{al}^{13}$ reviewed 12 studies published until 2006 and the results of the European VSD registry reported technical procedural success rates of $87-100 \%$ with major complication rates of $0-15 \%$ and the need for pacemaker implantation in $0-8 \%$ of patients. The investigators also reported on 430 patients collected on an intention to-treat basis from 23 tertiary referral centers as part of a registry. The patients included 119 muscular, 250 membranous, 16 multiple, and 45 postoperative residual VSDs. The overall procedural success was $95.3 \%$. There were early complications in 55 patients $(12.7 \%)$ with significant complications in 28 patients $(6.5 \%)$. One death was reported $(0.2 \%)$, vascular complications in $0.7 \%$ patients, hemolysis in $1.2 \%$ patients, infection in $0.5 \%$ patients, device embolization in $0.9 \%$ patients and early complete heart block $(\mathrm{CHB})$ in $2.8 \%$ patients. Complete closure of the VSD was achieved in $65 \%$ of patients by discharge and in $83 \%$ at a median follow up time of $2 \mathrm{yrs}$. The majority of the residual shunts were trivialor mild and only 3 patients $(0.7 \%)$ were subsequently referred for surgery.

Several studies on VSD device closures in China ${ }^{14-17}$ with Amplatzer devices or the Chinese occluders were reported. Majority of the patients were perimembranous VSDs patients. They reported a procedural success of $94.9 \%$ to $99.8 \%$ with an overall success rate of $98.6 \%$. The amount of residual shunt $>2 \mathrm{~mm}$ during follow up ranged from $0 \%$ to $4.7 \%$. Adverse events were reported to occur in $2.5 \%$ to $19.3 \%$ of patients with major complications ranged from $0.6 \%$ to $10.9 \%$. CHB occurred in $0.1 \%$ to $7.6 \%$ of patients with the vast majority being transient or responded to steroid therapy. Pacemakers were implanted in $5 / 2079$ patients $(0.2 \%)$ in these studies.

Holzer et $\mathrm{al}^{18}$ reported the results of a large international registry of perimembranous VSD closure using the 
Amplatzer Perimembranous VSD device. One hundred patients were enrolled with procedural success in $93(93 \%)$. Immediately after the procedure, complete closure was present in $58.1 \%$ of patients with $<2 \mathrm{~mm}$ shunt in $98.7 \%$. Transient $\mathrm{CHB}$ was noted in 2 patients and an additional 2 experienced $\mathrm{CHB}$ requiring pacemaker implantation. Therefore, a total of $4 \%$ of patients experienced $\mathrm{CHB}$ with $2 \%$ and required pacemaker implantation.

Device closure of subarterial VSD is considered difficult to accomplish due to its proximity to the aortic valve with possible impingement and subsequent development/ worsening aortic regurgitation; therefore, surgical closure is recommended in most cases. Device closure of sub arterial VSD with Amplatzer Duct Occluder is technically feasible and safe in patients older than 7 years of age. However, development or worsening of aortic regurgitation necessitates long-term follow-up. ${ }^{19}$ Placement failure was experienced by $5.1 \%$ of patients as a result of proximity to the aortic valve and acute insufficiency, chordae of the tricuspid valve, and inability to pass the delivery sheath. ${ }^{20}$ In contrast to perimembranous VSD, where device closure could cause atrioventricular block, the location of sub arterial VSD is far away from the conduction system atrioventricular block could be avoided. ${ }^{19}$

Muscular VSDs present a particular challenge to surgical closure. Various surgical techniques have been attempted, including right atrial, right ventricular, and left ventricular approaches. The first two provided poor visualization of the defects due to the heavy trabeculations of the RV. The latter, although provides better exposure, has been associated with significant ventricular dysfunction. ${ }^{21,22}$ In addition, the various surgical options are associated with high morbidity and a significant incidence of residual shunts. ${ }^{23}$ Device closure has been contemplated as a better alternative. The complications encountered in device closure of muscular VSD using an AVSDO are transient arrhythmias that occurred during or soon after the procedure. ${ }^{24,25}$ In this study we have a very good success rate in device closure of muscular VSD.

Post infarct VSDs (PIVSD) have a particularly poor prognosis with mortality rates for medically treated patients of $94 \%$ at 30 days post infarct and $97 \%$ at 1 year post infarct. ${ }^{9}$ Survival following surgical repair is likewise quite poor with mortality rates of $47 \%$ at 30 days and $53 \%$ at 1 year post infarct. ${ }^{9}$ Device closure of PIVSD compares favorably with surgical VSD closure and therefore trans-catheter VSD closure has emerged as a reasonable alternative to surgical management in these patients. ${ }^{4} \mathrm{We}$ have yet to do device closure of PIVSD in our center.

Retrospective in nature, single center study, nonrandomized study, with relatively small patient's population without long term follow up are the major limitations of this study.

\section{CONCLUSION}

In our experience, we have an excellent success rate of VSD device closure rate with low incidence of serious adverse event. Device closure of VSD is a valuable option in carefully selected patients. It can avoid cardiopulmonary bypass, surgical risk and a surgical scar.

\section{REFERENCES}

1. Minette MS and Sahn DJ. Ventricular Septal Defects. Circulation 2006; 114: 2190-2197.

2. Fyler DC. Ventricular septal defect. Nadas' Pediatric Cardiology Philadelphia, PA: Hanley \& Delfus, Inc, 1992;435-457.

3. Moller JH, Moodie DS, Blees M, Norton $\mathrm{J}$ and Nouri S. Symptomatic heart disease in infants: comparison of three studies performed during 1969-1987. Pediatric cardiology 1995; 16:216-222.

4. Balzer D. Current Status of Percutaneous Closure of Ventricular Septal Defects. Pediatrics \& Therapeutics 2012; 2:112.

5. Soto B, Becker AE, Moulaert AJ, Lie JT and Anderson RH. Classification of ventricular septal defects. British Heart Journal 1980; 43:332-343.

6. Graham TP and Spach MS. Ventricular Septal Defect. Heart disease in Infants, Children and Adolescents Baltimore, BA: Williams \& Wilkins, 1989; 192.

7. Assad AlH, Eltohami A, Gendi SM, El Yemeni Y, Nuhman MT and Hijazi Z. Transcatheter Closure of Perimembranous and Muscular Ventricular Septal Defects in Children with the Amplatzer Occluder: Experience in Qatar. Heart Views 2003; 4:3.

8. Herrador JA, Lezo JSD, PanM, Romero M, Segura J and Mesa D. Percutaneous Transcatheter Closure of Ventricular Septal Defects Using an Amplatz Device. Revista Española de Cardiología 2006; 59:510-514.

9. Crenshaw BS, Granger CB, Birnbaum Y, Pieper KS, Morris DC, Kleiman NS, et al. Risk factors, angiographic patterns, and outcomes in patients with ventricular septal defect complicating acute myocardial infarction. Circulation 2000; 101:27-32.

10. Berry C, Hillis WS and Knight WB. Transcatheter closure of a ventricular septal defect resulting from knife stabbing using the Amplatzer muscular VSD occluder. Catheterization and Cardiovascular Interventions 2006; 68:153-156.

11. Suh WM and Kern MJ. Transcatheter closure of a traumatic VSD in an adult requiring an ASD occluder device. Catheterization and Cardiovascular Interventions 2009; 74:1120-1125.

12. Minette MS and Sahn DJ. Ventricular Septal Defects. Circulation 2006; 114:2190-2197.

13. Carminati M, Butera G, Chessa M, Giovanni JD, Fisher G, Gewillig M, et al. Transcatheter closure of congenital ventricular septal defects: results of the European Registry. European Heart Journal 2007; 28:2361-2368.

14. Yang J, Yang L, Wan Y, Zuo J, Zhang J, Chen W, et al. Transcatheter device closure of perimembranous ventricular septal defects: mid-term outcomes. European Heart Journal 2010; 31:2238-2245.

15. Zuo J, Xie J, Yi W, Yang J, Zhang J, Li J, et al. Results of transcatheter closure of perimembranous ventricular 
septal defect. The American Journal of Cardiology 2010; 106:1034-1037.

16. Zheng Q, Zhao Z, Zuo J, Yang J, Wang $\mathrm{H}$, Yu S, et al. A comparative study: Early results and complications of percutaneous and surgical closure of ventricular septal defect. Cardiology 2009; 114:238-243.

17. Wei $Y$, Wang $X$, Zhang $S$, Hou L, Wang $Y, X u Y$, et al. Transcatheter closure of perimembranous ventricular septal defects (VSD) with VSD occluder: early and mid-term results. Heart and Vessels 2012; 27:398.

18. Holzer R, Giovanni JD, Walsh KP, Tometzki A, Goh T, Hakim F, et al. Transcatheter closure of perimembranous ventricular septal defects using the amplatzer membranous VSD occluder: immediate and midterm results of an international registry. Catheterization and Cardiovascular Interventions 2006; 68:620-628.

19. Shyu TC, Lin MC, Quek YW, Lin SJ, Saw HP, Jan SL, et al. Initial experience of transcatheter closure of subarterial VSD with the Amplatzer duct occluder. Journal of the Chinese Medical Association 2017; 80:487-491.

20. Arora R, Trehan V, Kumar A, Kalra GS and Nigam M. Transcatheter closure of congenital ventricular septal defects: experience with various devices. Journal of Interventional
Cardiology 2003; 16:83-91.

21. Kitagawa T, Durham LA, Mosca RS and Bove EL. Techniques and results in the management of multiple ventricular septal defects. The Journal of Thoracic and Cardiovascular Surgery 1998; 115:848-856.

22. Seddio F, Reddy VM, Mc Elhinney DB, Tworetzky W, Silverman NH and Hanley FL, et al. Multiple ventricular septal defects: how and when should they be repaired? The Journal of Thoracic and Cardiovascular Surgery 1999; 117:134-139.

23. Wollenek G, Wyse R, Sullivan I, Elliott M, de Leval M and Stark J. Closure of muscular ventricular septal defects through a left ventriculotomy. European Journal of Cardio-Thoracic Surgery 1996; 10:595-598

24. Hijazi ZM, Hakim F, Al-Fadley F, Abdelhamid J and Cao QL. Transcatheter closure of single muscular ventricular septal defects using the Amplatzer Muscular VSD Occluder: Initial results and technical considerations. Catheterization and Cardiovascular Interventions 2000; 49:167-172.

25. Thanopoulos BD, Tsaousis GS, Konstadopoulou GN and Zarayelyan AG. Transcatheter closure of muscular ventricular septal defects with the Amplatzer Ventricular Septal Defect Occluder: Initial clinical applications in children. Journal of the American College of Cardiology 1999; 33:1395-1399.

\section{Authors Contribution:}

CMA-Concept and design of the study, manuscript preparation, statistically analyzed and interpreted, Critical revision of the manuscript; MS- Concept and design of the study, critical revision of manuscript and review of the study; SCS- Reviewed the literature, helped in preparing first draft of manuscript; AB- Reviewed the literature, helped in preparing first draft of manuscript, collected data; SD- Reviewed the literature, helped in preparing first draft of manuscript; KPA- Collected data, statistically analyzed and interpreted, helped in preparing first draft of manuscript; PS- Reviewed the literature, helped in preparing first draft of manuscript; SA-Collected data and reviewed the literature; US- Collected data, statistically analyzed and interpreted, helped in preparing first draft of manuscript.

\section{Work attributed to:}

Department of Cardiology, Shahid Gangalal National Heart Centre Kathmandu, Nepal.

\section{Orcid ID:}

Dr. Chandra Mani Adhikari - (1) https://orcid.org/0000-0001-5811-9977

Dr. Kiran Prasad Acharya - (i) https://orcid.org/0000-0003-2765-4242

Source of Support: Nil, Conflict of Interest: None declared. 